\title{
Chapter 5 Transcendental Idealism and the Transcendental Deduction
}

\author{
Lucy Allais
}

"Kant was not the sort of person who had the intellectual courage to face up to a dilemma and reject one alternative in favour of the other. Instead, when he felt himself pulled in opposite directions by conflicting imperatives, his preference was to try to work out some way of satisfying both. This intellectual 'cowardice' [...] is the characteristic that led Kant to his most brilliant discoveries" (Falkenstein 1995, 19). This is Lorne Falkenstein's diagnosis of the impetus of Kant's intellectual development. Apart from the pejorative language, this seems to me to capture one of the most compelling features of Kant's thought, as well as being, in general, a philosophical strategy with a good prospect of leading us to the truth. It also seems to me to be a good strategy to use when interpreting Kant: when facing the various and sometimes radically opposed interpretations philosophers have given of Kant's transcendental idealism, we should start by assuming that there are genuine interpretative pulls to the opposed positions, and try to come up with an interpretation that respects them.

As everyone knows, there is no agreement in interpretations of Kant's transcendental idealism, not even a tendency to convergence, and recent publications continue to represent an astonishingly wide spectrum of views. On the one extreme, we have interpretations which see Kant as a phenomenalistic or Berkeleyan idealist about things as they appear to us, and on the other extreme we have deflationary or epistemic interpretations, which do not see Kant as any kind of idealist at all. Here are two examples: Arthur Collins says that "Kant is not an idealist" (Collins 1999, 2), and that "[a]n interpretation that finds a kind of idealism in Kant, that ascribes to him a reduction of objects to mental representations [...] fails to capture the originality, profundity, and merit of his thought" (Collins 1999, 3). On the other side of the spectrum, James Van Cleve says: "As I interpret him, then, Kant's transcendental idealism is idealism indeed, at least regarding everything in space and time" (Van

\footnotetext{
L. Allais ( $\otimes)$

Department of Philosophy, University of Sussex, Brighton BN1 9RH, UK; Department of Philosophy, University of the Witwatersrand, Johannesburg 2050, South Africa e-mail: 1.1.allais@sussex.ac.uk; lucy.allais@wits.ac.za 
Cleve 1999, 4), and that "objects in space and time are logical constructions out of perceivers and their states. That makes Kant a phenomenalist" (Van Cleve 1999, 11). ${ }^{1}$ I have argued elsewhere that taking seriously the interpretative pulls which support both extreme views enables us to chart a middle road between them which makes sense of the textual evidence that seems to support the extremes. ${ }^{2}$ According to this middle road position, transcendental idealism is a form of metaphysical idealism, which says that things as they appear to us depend on our minds, but it is not the extreme form of idealism-Berkeleyan idealism-which says that things exist as ideas in the mind. Deflationary interpreters do not see transcendental idealism as an ontological position at all, which of course the strongly idealist interpreters do. Here again, I think we should try to incorporate insights made by both sides. Surely transcendental idealism is a position with both epistemological and metaphysical components. Another set of extremes in approach is between those who, like P.F. Strawson (1966), think that everything that is of value in the Critique can be entirely separated off from Kant's transcendental idealism, and those who feel that seeing Kant's central arguments as not dependent on or leading to his idealism is to fail to take transcendental idealism seriously, and to miss the coherence of Kant's work (perhaps Sebastian Gardner [1999] is an example of this approach). I think we should take transcendental idealism seriously for it is clearly key to many of Kant's arguments and positions in the Critique. But it is compatible with this that Kant may have some arguments and epistemological insights which are separable from his idealism.

In this article, I briefly outline the middle road interpretation of transcendental idealism which I have been attempting to develop, ${ }^{3}$ and then begin to look at its relation to the Transcendental Deduction of the categories. Given the less than entirely clear nature of Kant's argument in the Deduction, the relation between his transcendental idealism and the Deduction is extremely complicated; I give some reasons for thinking that the argument of the Deduction might not depend on transcendental idealism, and that at least one line of thought in the Deduction may be applicable even from the point of view of realism. I do not intend to attempt to give an account of the argument of the Deduction as a whole.

\section{2}

The middle road version of transcendental idealism I have been trying to develop is one which sees Kant as an ontological idealist, since the empirically real world (things as they appear to us) depends on our minds, but not as an extreme

\footnotetext{
${ }^{1}$ The debate is not just between phenomenalist and non-idealist interpretations; to mention just two other possible interpretations, Paul Abela (2002) argues that transcendental idealism does not involve idealism because it is an epistemological position, involving the rejection of the so-called given, while Rae Langton (1998) sees transcendental idealism as an ontological position, but one which does not involve any kind of idealism, but rather concerns a distinction between extrinsic and intrinsic properties.

${ }^{2}$ Allais (2007).

${ }^{3}$ This is a brief summary of the view I develop in depth in Allais (2007).
} 
Berkeleyan-type idealist, who thinks that empirically real objects exist merely as collections of mental states (organized according to a priori principles and a priori forms of intuition), or something which supervenes on mental states. One of the central challenges to this kind of view is to give an account of a kind of minddependence which does not involve existence in the mind, and I have attempted to do this by drawing on the analogy with color that Kant suggests in the Prolegomena (AA 4: 289). ${ }^{4}$ In the relevant passage, Kant says that the idea that there are some qualities, like color, that belong only to the appearances of things, and not to things as they are in themselves, is commonly accepted. He then says that his view is that all the properties which make up the intuition of an object belong merely to its appearance. Of course, there are many possible views of the ontological status of so-called secondary qualities like color, and the passage is compatible with more than one, leading to different interpretations of what it would mean to say that size and shape are relevantly like a secondary quality account of color. My suggestion is that we need an account of color which is situated within a direct realist view of perception, and therefore does not think of colors as properties that exist merely in the mind, but which at the same time allows that some of the properties we directly perceive are mind-dependent, and do not present things as they are in themselves. If such a view is available, we can then explain Kant's position by generalizing this view of secondary qualities to apply to all the appearance properties of objects, which is what he suggests in the Prolegomena passage. This will give us a view which includes genuine metaphysical mind-dependence (idealism), but not of the extreme, Berkeleyan sort.

Clearly, how we understand secondary qualities will be crucial. If we have an indirect view of perception and locate color in representational mental states which exist merely in the mind, then the analogy will lead to the Berkeleyan view of Kant's idealism. To avoid Berkeleyan idealism, we need an account of secondary qualities situated within a direct realist view of perception. But it is important to see that drawing on a direct realist view of perception to explain the desired view of secondary qualities need not lead to denying that Kant is an idealist, so long as we can find a way of making sense of directly perceiving properties, which are properties of outer objects but are mind-dependent properties of outer objects. The direct realism is merely the first step. I draw on the work of John Campbell, a straightforward realist, to illustrate the view of perception within which we should situate the account of secondary qualities we need; he calls this a relational view. The point of the term 'relational', here, is to mark out as essential the idea that the conscious representational mental states which are involved in perceiving something have as their content the actual object perceived, not a representation of it which could be had whether or not the object was present. On the indirect realist view, mental states have representational content, which is perceptional when it has, for example, the

\footnotetext{
${ }^{4}$ See Allais (2007); cf. Rosefeldt (2007) for a very similar account, as well as Ameriks' contribution to this volume. Van Cleve (1995) argues that no version of the secondary quality analogy enables us to make sense of Kant's idealism. See Putnam (1981) for a different use of the secondary quality analogy.
} 
right causal relations to objects. On the relational or direct view, the content of perceptional states essentially involves the presence of the object to consciousness.

One of the features of Campbell's account that is particularly helpful for our purposes here is the fact that he is trying to do justice to the extent to which our knowledge of cognitive processing seems to support indirect realism, and to showing why it need not. This is crucial in a Kantian context because of how active Kant thinks the mind is in constructing our experience of the world; Kant thinks that our minds need to synthesize and organize the sensory input on a variety of levels, and it is by no means obvious that all of these are supposed to lead to idealism. It seems to me that, just as our knowledge of cognitive processing seems to support indirect realism in the contemporary debate, this aspect of Kant's thought seems to, but in fact need not, support seeing Kant as a phenomenalistic idealist. This will be crucial when we come to the Deduction.

Campbell suggests a metaphor to illustrate the relational view of perception: think of viewing something through a pane of glass. For a representationalist, perception will involve images on the glass that represent the things beyond the glass, but for a relational view we see straight through the glass to the objects themselves. As Campbell points out, knowledge of cognitive processing seems to tell us that, unlike a passive pane of glass, the brain is actively involved in constructing a representation of the world, and this seems to threaten the idea that perception can be analogously like seeing through a pane of glass. In response, he suggests the following development of the metaphor:

\begin{abstract}
Suppose we have a medium which, like glass, can be transparent. But suppose that, unlike glass, it is highly volatile, and needs constant adjustment and recalibration if it is to remain transparent in different contexts. Suppose, in fact, that the adjustment required is always sensitive to the finest details of the scene being viewed. The upshot of the adjustment, in each case, is still not the construction of a representation on the medium of the scene being viewed; the upshot of the adjustment is simply that the medium becomes transparent. You might think of visual processing as a bit like that. It is not that the brain is constructing a conscious inner representation whose intrinsic character is independent of the environment. It is, rather, that there is a kind of complex adjustment that the brain has to undergo, in each context, in order that you can be visually related to the things you see around you; so that you can see them, in other words. (Campbell 2002, 119)
\end{abstract}

The metaphor is supposed to give us an intuitive take on the idea that perception could be direct, despite what we know about cognitive processing. We know, for example, that color and shape are processed in different streams in the brain, and that the information received by the sense organs then needs to be recombined in order for us to perceptually represent an object with both a shape and a color. Campbell's metaphor is supposed to help us to see that we do not have to take this to show that we see the world by producing an inner image in which the color and shape are combined; rather, the idea is that mental processing enables us to directly see the colored and shaped object in the world.

The next step is to find a way of fitting into this account the idea that some of the directly perceived properties of things are mind-dependent, and are not properties things have as they are in themselves, independently of our being able to perceive 
them. I suggest extending the metaphor in the following way: imagine that a malfunction in the adjustment mechanism causes the medium to fail to be completely transparent, but instead distorts the shapes of things to some extent, as for example a fishbowl lens might. Just as when the medium is transparent, it is not the case that the distorted things are seen through seeing an image on the glass-it is the things that are directly seen, through the distorted glass. If seeing things transparently essentially involves the presence of the objects, this is also the case when their shapes are seen in a distorted way. However, in this case the things are seen as being, to some extent, different from the way they are, apart from their being seen. If we allow this possibility, then thinking that seeing an object is relational, in the sense that the object is essentially present to consciousness, does not entail that seeing an object is necessarily transparent, in the sense that the way the object is seen as being is the way it is apart from its being seen.

Here we have an account according to which we experience things in ways which are different from the way they are in themselves, and which are mind-dependent in the sense that they do not exist apart from our possible perception. This is exactly what Kant says about things as they appear to us. The next step is to generalize this to all the properties of which we have knowledge and experience. This results in an account on which we experience only mind-dependent appearances of things, but these appearances do not exist in the mind like thoughts.

So far, I have not mentioned the specific concerns with apriority that lead Kant to his position. That's because I am trying to explain a general sense in which things as they appear to us could be mind-dependent representations, rather than to give an account of Kant's argument for this view. Kant thinks that we could not experience individual objects without experiencing them as located in a spatiotemporal framework, and that the a priori nature of this framework means that it cannot be taken as reflecting mind-independent reality, but rather must be something brought to the world by our minds. If the structure which enables us to experience individual things is not a reflection of the world as it is in itself, neither will the things we are able to perceive through this structure be. To return to the metaphor, imagine that in order to perceive individual objects through the pane of glass, the glass has to have a built-in structure which determines how what we see through the glass is grouped together as objects. It is still the case that we are seeing through the glass, to the world outside our minds, but the way we are seeing it, and even what we are seeing as an object, is now dependent on the way our minds are and does not let us experience objects as they are in themselves.

\section{1}

So far Kant's idealism has been explained in terms of the contributions of the a priori forms of our intuition, and nothing yet has been said about how the categories determine our experience. I now want to move on to make some tentative remarks 
about the Transcendental Deduction of the categories. One way in which the relation between the Deduction and transcendental idealism is complicated is that many people think that key sections of the argument in the Deduction depend on transcendental idealism, ${ }^{5}$ but, on the other hand, the most straightforward account of Kant's argument for his transcendental idealism suggests that the idealism follows from the result of the Deduction. Immediately following the Deduction (A129, B167) Kant presents his standard, central argument for transcendental idealism: that it provides the explanation of our having substantive a priori knowledge. This suggests that the idealism follows from the results of the argument of the Deduction, rather than being assumed by it. This reading straightforwardly parallels the structure of the argument in the Aesthetic, where Kant argues that our being presented with distinct particulars in empirical intuition requires our having an a priori structuring intuition, and then argues that the only explanation of substantive a priori knowledge is that it is not knowledge of something mind-independent, and therefore that space and time are merely the a priori forms of our intuition, and so are transcendentally ideal. Similarly, it could be that the Deduction is supposed to establish that certain a priori concepts apply to all objects of possible experience; transcendental idealism is supposed to follow as the explanation of our having a priori concepts that apply to the world.

Gardner argues that failing to see the Deduction as depending on transcendental idealism means not taking transcendental idealism seriously, as well as not taking seriously the coherence of Kant's thought (Gardner 1999, 118, 120), and he cites a number of passages which he says show that the argument of the Deduction depends on transcendental idealism (Bxvii, A92-94=B124-127; A95-97; A111; A114; A128-130; B163-164; B166-168; A139=B178; A180-181=B223-224; Prol. §§26-30). While all these passages clearly connect transcendental idealism and the categories, it seems to me that apart from one, the order of explanation is the reverse of what Gardner presents: these passages give expression to Kant's official direct argument for transcendental idealism, which follows from our having a priori knowledge, and therefore presumably could not be used as a premise of an argument establishing that we have such knowledge (the exception is A111, which I discuss below ${ }^{6}$ ). For example, in the B-preface, Kant famously says that

\footnotetext{
${ }^{5}$ See, for example, Andrew Ward, who argues that, for Kant, the idea of experience of a world without causation is not coherent, "once it has been realised that the objects of perception are appearances, and never things in themselves" (Ward 2006, 52). See also Gardner, who says that the Deduction "is an account of how the world is (must be) constructed conceptually on the assumption that the fundamental conceptual features of the objects of our cognition derive from our mode of cognition, rather than being determined by how things are independently of our subjectivity" (Gardner 1999, 120).

${ }^{6}$ However, I do agree with Gardner that there are numerous passages in the Deduction which at least seem to be premised on transcendental idealism, some of which I discuss below. He chooses the passages which most directly link the Deduction with transcendental idealism, but it seems to me that while the link is direct, the order of explanation is the reverse of what he presents it as. Gardner says that seeing the argument of the Deduction as premised on transcendental idealism "goes back to the general case for making the Copernican experiment in philosophy" (Gardner
} 
if we assume that concepts conform to objects, we have difficulty explaining how we could know anything about them a priori, whereas this can easily be explained if objects conform to our concepts: the idealism is the explanation of our having synthetic a priori knowledge. Simply and roughly put, Kant argues first that our cognition has various a priori conditions, and then says that this is possible only if our minds determine objects, and thus reaches his idealist conclusion. Clearly, thinking that the Deduction is supposed to lead to transcendental idealism in no way involves failing to take transcendental idealism seriously, or denying that it is closely bound up with Kant's concern in the Deduction.

Another problem with the relation between the Deduction and transcendental idealism is that, despite the apparently similar role in constituting our experience that Kant attributes to the a priori intuitive and conceptual contributions to experience in the B preface (Bxvii), when we look at the details of the arguments put forward in the Transcendental Aesthetic and the Transcendental Analytic, as well as the conclusions Kant draws from them, this straightforward parallel is no longer so clear. ${ }^{7}$ In terms of the respective roles categories and intuitions play in cognition, the way they feature in the argument for transcendental idealism, and in terms of the explicit conclusions Kant states about a priori forms of intuition and a priori concepts at the ends of the sections in which he argues for them, it is not clear that the categories are supposed to introduce an additional kind of mind-dependent structuring to the objects of experience, parallel to that introduced by the a priori forms of intuition. It is arguable that Kant's aim is to show that the categories are limited to spatiotemporal appearances (and therefore to the mind-dependence introduced by space and time), and not that they constitute further mental contributions to the nature of the objects of experience.

The lack of parallel is most obvious with respect to the conclusions Kant presents at the end of the sections in which he argues for a priori forms of intuition and a priori concepts, respectively. At the end of his argument in the Aesthetic, immediately following the argument for space and time being merely our forms of intuition, Kant's explicit conclusion is that space and time are merely the a priori forms

1999, 120), but it seems to me that the general case for the Copernican experiment gets the order of explanation the other way around: from a priori knowledge to idealism.

${ }^{7}$ For extremely helpful discussion of the lack of parallel between the categories and a priori intuition see Eric Watkins (2002) and Thomas Pogge (1991), who both argue that this is something to which commentators have not paid enough attention (Watkins 2002, 196; Pogge 1991, 493). Gerold Prauss (1974) is one commentator who does comment on this issue; he seems to see it as a question of presentation, and as a hang-over from the Inaugural Dissertation, in which Kant sees the objects presented to us in sensibility as mind-dependent, but still thinks that reason can give us knowledge of reality in itself (Prauss 1974, 59, 59n.12). But the fact that the full critical position goes beyond the Inaugural Dissertation in denying that reason can give us cognition of things in themselves is compatible with more than one account of the role of the categories: it could be that the categories add an extra 'layer' of mind-dependence, in that they structure objects in a parallel way to the way the a priori forms of intuition do, or it could simply be that the categories are limited to the mind-dependent objects presented to us by sensibility (which still takes us beyond the argument of the Inaugural Dissertation). 
of our intuition, and that they represent no features at all of things in themselves $(\mathrm{A} 26=\mathrm{B} 42)$. If the categories are supposed to have a parallel status, we should expect him to say, at the end of the Deduction, that they represent no properties at all of things in themselves, but this is not exactly what we find him saying. Instead, immediately following the Analytic, in the section 'On the ground of the distinction of all objects in general into phenomena and noumena', Kant says that an important result of the Transcendental Analytic is that the categories cannot be used other than for knowledge of objects of experience (A246=B303). In other words, we can use these a priori concepts only for cognition of spatiotemporal objects, objects which affect our senses. Rather than saying that the categories represent no feature of things in themselves, Kant says that the categories are limited to objects that can be given to our spatiotemporal intuition.

Another worry about making the argument of the Deduction assume transcendental idealism is that this might be thought to make the argument too easy, and the result unsatisfying. The argument seems too easy, because it seems that all we need is transcendental idealism plus the metaphysical deduction, and we will already have the results of the transcendental deduction: we think of objects in terms of certain a priori concepts; the objects of experience are appearances which depend on the a priori concepts we use to think about them; therefore these a priori concepts apply to the objects of experience. ${ }^{8}$ On this reading, the result of the Deduction seems unsatisfying, because we wanted to show "how the subjective conditions of thinking should have objective validity" (A89-90=B122), ${ }^{9}$ which seems to involve showing that these concepts are more than simply features of the way we think, and in fact actually apply to objects, the world. Compared with the tortuous argument of the Deduction, the idea that the subjective conditions of thinking apply to objects simply because objects are a function of the subjective conditions of thinking, again, seems much too quick and easy.

On the other hand, a reason to think that the Deduction does assume and require transcendental idealism is that it is situated after the Aesthetic, in which the idealism is supposed to be established, and might reasonably be thought to assume the results of the Aesthetic. And there are certainly passages in the Deduction that support thinking that it relies on transcendental idealism; for example, Kant says that " $[t]$ he a priori conditions of a possible experience in general are at the same time conditions of the possibility of the objects of experience" (A111). One way of responding to this, which attempts to incorporate the reasons on both sides, is to say that the argument of the Deduction relies on idealism with respect to the forms of

\footnotetext{
${ }^{8}$ Roughly, Kant's strategy in the Metaphysical Deduction seems to be to argue (1) that we have certain fundamental ways of thinking; (2) that concepts are ways of synthesizing experience; (3) concepts involve synthesizing experience in the same way that judging involves bringing ideas together in thought; (4) this means that if we have certain fundamental ways of thinking, we will have certain fundamental concepts we will use for organizing our experience. However, it does not follow from this that these concepts actually apply to the world that we experience, and we therefore need a transcendental deduction to demonstrate that they do. But if we start by assuming that experience is a function of the concepts that we use, then it seems that we do already know that these concepts apply to the world that we experience, and the Deduction is unnecessary.

${ }^{9}$ All translations from the Critique of Pure Reason are from the Guyer and Wood edition (Kant 1998).
} 
intuition, but not with respect to the forms of thought. In other words, the argument starts by assuming that we do not have knowledge of things as they are apart from their appearing to us, and that things as they appear to us depend on the a priori form of our intuition, but does not assume that things as they appear to us are determined by the a priori concepts we require for cognition of an objective world.

Another way of seeing the Deduction as assuming only some aspects of transcendental idealism, is to say that it takes as a starting point the idea that we can have knowledge only of objects which are given in experience. ${ }^{10}$ Some commentators seem to see this as an account of Kant's transcendental idealism as a whole. For example, Graham Bird says that Kant "is a transcendental idealist because [he thinks] it is quite unwarranted to make claims about objects which are not open to any sort of perceptual inspection"; "Kant's empirically neutral term 'appearance' was thus designed to limit the range of our possible experience to the objects that can be presented to our senses" (Bird 1962, 50, 148). ${ }^{11}$ Limiting our knowledge to things that can be presented to our senses is clearly a crucial part of Kant's position, and constitutes his rejection of transcendent metaphysics, but, on its own, this is an epistemological claim with no commitment to idealism. On my account of transcendental idealism, Kant's position goes beyond this, but it is compatible with this that the argument of the Deduction relies on this aspect of the position, and not on all aspects of transcendental idealism. It might be that the argument of the Deduction assumes that we can have knowledge only of things given in experience, so it does start by assuming that transcendent metaphysics is impossible, but it does not start by assuming that the world that we experience is determined by our a priori concepts, and has no existence apart from our possible experience of it. ${ }^{12}$

Kant's insistence in the Deduction that the categories relate solely to appearances, and that they do not relate to "objects in general," "without any restriction to

\footnotetext{
${ }^{10}$ This is compatible with the fact that Kant expresses his view by saying that we have knowledge only of appearances, because there is nothing in the notion of things as they appear to us that rules out the way they appear to us matching the way they mind-independently are. Rather, the notion can be seen as simply picking out that class of things, or those aspects of things, of which we have experience-which appear to us. Kant does not simply rely on the notion of things appearing to us in certain ways to establish his idealism, but gives specific arguments as to why he thinks things do not appear to us as they are in themselves.

${ }^{11}$ Similarly, Dryer claims that when Kant says that the conditions of the possibility of experience are conditions of the possibility of objects of experience, he means "that conditions under which it is possible to secure empirical knowledge are also conditions under which it is possible for what exists to become objects of empirical knowledge" (Dryer 1966, 500; see also 84-85, 506). This fits Kant's claim, at the beginning of the Deduction, that the representation does not make the object possible so far as existence is concerned, but is "still determinant of the object a priori if it is possible through it alone to cognize something as an object" (A92=B125). The idea seems to be that the categories are necessary for something to be an object of knowledge, which is a substantive and interesting idea, but not one which implies idealism.

${ }^{12}$ As Longuenesse argues, "whereas the ontology of Aristotelian inspiration defended by Kant's immediate predecessors in German school-philosophy purported to expound, by a priori arguments, universal features of things as they are in themselves, Kant's more modest goal is to argue that our understanding is so constituted that it could not come up with any objective representation of things as they present themselves in experience, unless it made use of the concepts expounded in his table of categories" (Longuenesse 2006, 129; see also A247=B303). Kant might think that this
} 
our sensibility" (A139=B178), can be read along these lines. His point is to deny that we can have a priori knowledge of things which are not possible objects of experience (which do not appear to us), and to insist that our concepts require the content given by being presented with objects in intuition. These substantive claims are an important part of Kant's position, but they need not involve idealism. As noted at the beginning, Kant's concerns are both epistemological and metaphysical, and we need not insist that every aspect of every argument involves both.

In addition to the idea that the argument of the Deduction need not rely on all aspects of transcendental idealism, it is important to notice that Kant does not think that all parts of the argument lead to idealism. For example, his insistence on the idea that our experience of the world requires synthesis at a variety of levels, from mere perception to empirical concept application, ${ }^{13}$ is not taken by him to lead to idealism, so long as this synthesis happens at the empirical level. Just as we need not take our knowledge of cognitive processing to undermine direct realism, Kant does not conclude merely from his insights into the activity of the mind in processing the input of the senses that this processing could not result in representing things the way they mind-independently are. The fact that the mind must actively process and combine the shape and color input of the senses to represent a tomato as a single round red thing does not mean that the tomato is not, as it is represented as being, a round red thing. Rather than basing his case on a general need for cognitive processing, as Karl Ameriks has stressed, Kant's argument for his idealism is always based on his specific concerns with apriority: it is when the activity of the mind requires an a priori component, such as a priori synthesis, that it cannot be taken as indicating the way things mind-independently are. ${ }^{14} \mathrm{~A}$ similar point applies to Kant's claim that concepts express the unity of synthesis (A78=B104): the point surely is meant to apply to all concepts, empirical as well as a priori. Kant thinks that all concept application involves, in some sense, a unity in consciousness (A103104), but does not argue on this basis for idealism.

One line of thought in the Deduction which might be thought to depend on transcendental idealism is Kant's argument that because appearances are sensible representations and not things in themselves, an object corresponding to and therefore also distinct from cognition would merely be something in general $=\mathrm{x}$, and therefore that the necessity and unity that the object makes necessary must come from an a priori unity in consciousness (A104). However, it might be that even this argument can be read as relying on only some aspects of transcendental idealism; in particular, that we can know only objects which are given in experience, and we cannot have knowledge of anything that cannot be experienced. In the B-version of this argument, Kant says that:

line of thought leads to his idealism, but it does not depend on it; a realist could reject transcendent metaphysics.

${ }^{13}$ Kant says that combination can never come to us through the senses (B129) and "we can represent nothing as combined in the object without having previously combined it ourselves" (B129), and he does not say that this applies only to the level of a priori combination.

${ }^{14}$ Ameriks (1990); see also Ameriks (2006: 74; 2003: 102). 
An object, however, is that in the concept of which the manifold of a given intuition is united. Now, however, all unification of representations requires the unity of consciousness in the synthesis of them. Consequently the unity of consciousness is that which alone constitutes the relation of representations to an object, thus their objective validity, and consequently is that which makes them into cognitions, and on which even the possibility of the understanding rests. (B137)

This passage (and others like it) might be thought to express the idealist thought that empirical objects exist only as unified representations in minds, and has been taken this way. For example, P.F. Strawson (1966: 91) argues that Kant needs the categories because they are a kind of surrogate for the way that, for a realist, objects constrain our thought; this clearly sees the need for the categories as depending on transcendental idealism. Similarly, Cassam (1987: 367) argues that Kant's claim that the object itself is nothing to us follows from his idealism, and that this is his reason for introducing transcendental synthesis. However, I suggest that there may be another way of reading Kant's thought, which can be briefly and roughly sketched as follows. We start from the assumption that we need to be affected by objects to have cognition of them-that we can have cognition only of objects which appear to us in possible experience. Kant then says that having cognition of an object (being able to apply concepts to objects, and having experience of an objective world) requires a unity in consciousness that has some kind of necessity and universality. But, like both empiricists and rationalists, he thinks that necessity and universality cannot be learnt from experience. Therefore experience of objects requires a unity and necessity that cannot be empirically derived. Further, against rationalists, he thinks that our cognition is limited to objects which present themselves to our experience. This means that the necessity and universality which we need for cognition cannot be a result of insight into the way the world is, and it cannot be acquired from experience, and in this sense the object itself is nothing to us. Our experience of the object cannot provide us with the organizing principles we need to represent something as an object (I say a bit more about this in the next section).

My aim here is not to develop or assess this line of argument, but merely to see how it might relate to Kant's transcendental idealism. What should be noted is that, so far, the argument has made no appeal to idealism, rather, it relies on receptivity (the fact that we can have knowledge only of objects which affect our senses) together with the claim that necessity cannot be learned from experience, and the claim that the representation of an object requires a certain kind of necessity and universality. On my reading, if Kant's argument works, even a straightforward realist should agree that experience requires synthesis at the levels of perception and empirical concept application, and even a realist should see that experience of an object requires a unity and necessity in consciousness that cannot be derived from experience. If this is right, the argument assumes the rejection of transcendent metaphysics and the idea that we are receptive creatures who must be affected by things to have knowledge of them, but not necessarily Kant's complete idealist picture. And the argument leads to, rather than assumes, the idea that our minds must make an a priori conceptual contribution to experience. On this reading, the key step that we 
need to understand the Deduction - the contentious and so far unexplained stepis why we should think that experience of an object, or experience of an objective world requires thinking of objects with a kind of unity and necessity that cannot be given, and that is irreducible and non-empirical. This seems to me exactly the exciting and difficult heart of the argument of the Deduction; in the next section I make some suggestions about the kinds of considerations we might investigate to understand Kant's idea here.

\section{2}

Like Ameriks, I see the argument of the Deduction as starting from the assumption that we have empirical cognition, and therefore as not being anti-skeptical (Ameriks 2003). Kant assumes that we have experience of an objective world about which we can think and do science, and asks about the conditions of this. Further, the Deduction is specifically concerned with one aspect of cognition: the conditions under which we can apply concepts to objects in judgments. In the Aesthetic, Kant wants to show that a priori intuition is a necessary condition of being presented with distinct particulars in empirical intuition; in the Deduction, he wants to show that a priori concepts are necessary conditions of being able to apply empirical concepts in empirical judgments. ${ }^{15}$ This means that what we need to make sense of (at least part of) Kant's argument is, first, to understand what concept application in general contributes to cognition, and then to understand why this contribution at the empirical level should be thought to depend on the categories-why applying empirical concepts to objects might be thought to require a priori concepts.

There is a fairly common reading, perhaps the standard view, which sees Kant as thinking that the application of concepts, and in particular the categories, is necessary for the basic intentionality of perception, viz., the fact that we are perceptually presented with particulars outside us, things we experience as outside ourselves. This seems to me to leave out one of the layers of complexity in Kant's thought, and to undermine the point of the Transcendental Aesthetic. ${ }^{16}$ Kant clearly states that it is intuition through which objects are given, and a priori intuition which is necessary for us to be immediately presented with individuals that are experienced as distinct from and outside of me, distinct from each other, as spatially located, and as spatially related $(\mathrm{A} 23=\mathrm{B} 39) .{ }^{17}$ Thus, spatiality is necessary for us to be presented

\footnotetext{
${ }^{15}$ This means that the argument cannot proceed by pointing out the inadequacies of Humean association and concept imagism (this is too soft a target); rather, the opponent should be someone who allows that concepts are rules, but thinks that all we need to make sense of empirical knowledge are empirical concepts/rules.

${ }^{16}$ I argue this in detail in Allais (2009).

${ }^{17}$ For Kant, intuitions are importantly different from sensations. At least in the first Critique, he thinks of sensations as non-intentional, whereas intuitions always present a thing. A creature which had only sensations would not have experience of inner and outer at all, but it is a mistake to think that the next level of achievement would be being aware of having an inner life. Rather, I think Kant's insight is that a non-concept having creature could perceive things that are outside of it, but could not think about the world as objective, and could not be aware of its own mental life. It was objected to me that a non-concept having creature could not distinguish outer objects from
} 
with objects-for the fact that perception puts us in touch with a world, which, as Kant frequently reiterates, concepts alone cannot do.

It is important to see that thinking that we can be perceptually presented with located particulars independent of the application of concepts is completely compatible with thinking that we do not have determinate reference to an object without the categories. Consider an animal whose actions indicate that it sees a located, relatively spatially unified thing, which it can discriminate from other things, which (following spatial boundaries) it can track, and with respect to which it has some expectations of how it will act. Think, for example, of an animal following a moving insect. Attributing to the creature the capacity to perceptually discriminate the thing does not require thinking that it can think of the thing as a persisting and causally unitary substance, or that it can make general use of or attribute to other animals thoughts about the thing and its interactions in a general causal order. A non-concept-having creature, which can discriminate spatial boundaries, can perceive located particulars but it cannot think about them; it cannot attribute properties to them. This means that it cannot investigate their properties in the way that leads to science, it cannot think about things interacting with each other, and it cannot think about existence unperceived. Since it cannot think about and investigate the principles of unity, which distinguish physical objects from mere perceptual particulars (such as shadows or spots of light), it does not have determinate experience of objects.

Whether or not it is granted that Kant allows the possibility of perception in the absence of concepts, it seems uncontroversial that without concepts we do not have a relation to an object in the full-blown Kantian sense of something that is thought of as a persisting causally unitary substance whose properties are a function of its causal nature and its past experience. Whether Kant's view requires this level of sophisticated thought for basic perception is a separate question, and most of my argument does not depend on the more controversial claim that it does not. However, I think that if we allow, as seems straightforwardly compatible with the text, that Kant thinks that perceiving located particulars outside of you requires intuition, but is not the same as representing objects (persisting causal unities which are thought of as existing unperceived), we get a more interesting view of what concepts add: it is not the basic capacity to perceive particulars but thought - the capacity to apply empirical concepts to objects in judgments, and therefore to represent objects as having properties.

Kant says that concepts are what enable us to think objects. Concepts, for Kant, are essentially general: grasping a concept essentially means being able to combine it with other concepts in different thoughts. (A subject has not grasped the concepts in the judgment ' $a$ is $F$ ' if she is not also able to grasp the thought that $b$ is $F$, that $c$ could be $F$, that $a$ is $G$, and that $a$ could be $H$, and so on.) In representing an object as having a property, a subject is representing it as having a feature which, in principle, other things could have. Whether or not it is thought that concepts are

its own perceptions (Thad Metz, personal correspondence). I think the response is to say that it is not clear whether we should think of the non-concept having creature as aware of itself as having sensations, and therefore as aware of its sensations-it is aware of the world, but not of itself as having an inner life. 
necessary for a quality to be represented in perceptual experience (to be perceived), it seems clear that in the absence of concepts the quality does not feature in perceptual experience as a property (as a general feature, which other things may have). So even if we allow that the redness of an object could present itself in perceptual experience without the perceiver's having color concepts, once the perceiver has color concepts, she can represent the thing's redness in a new way. She can represent it as having a property which other red things have, and which other, non-red, things could have. She thus brings it into relationship with other objects, she recognizes and classifies it, and she can make judgments about it. This, arguably, fundamentally alters the perceptual experience of concept-having creatures: concept-having creatures represent objects as having general features.

Adding these general combinatorial possibilities to the experience of the animal is necessary to give it the capacity to think such thoughts as that 'this is the object I was looking at yesterday,' in the absence of which it is not able to think about existence unperceived, or to think about the objective temporal order. At a more basic level, being able to represent an object as having general features is, arguably, necessary to represent it as a determinate object. Distinct perceptual particulars are things which are represented as outside and other than the subject (unlike sensations), but they could be shadows, or spots of light; they need not be objects. Even when the things the non-concept-having creature is perceptually presented with are in fact objects, it is arguably not in a position to represent them as objects. For example, on the basis of my being perceptually presented with an apple, I could think either, 'that object is red' or 'that patch is red' or 'that redness is round.' The redness to which roundness may be attributed, the apple to which redness may be attributed, and the patch to which redness may be attributed will have different principles of continuing identity over time, and different properties will be attributable to each of them. Without something that determines what counts as a subject of properties for me, what principles of unity subjects have, etc., it is not determinate what object I am thinking about, even though there is a perceptual particular to which I am attending. Kant thinks that the a priori concepts of an object in general determine what counts as an object for me (B128-129), and this is necessary for me to have thought about the object, and to attribute properties to it in empirical concept application. Notice that this gives us a perfectly clear sense in which the categories are necessary for anything to be an object for me, which is distinct from thinking that the categories are necessary for me to be perceptually presented with a particular.

The idea that these a priori concepts determine what counts as an object for us might be thought to be a clear expression of a kind of idealism. However, I suggest that there might be a way of reading Kant's point as an epistemological point, which a realist could accept. Kant says that when we attribute properties to an object, we are doing more than simply associating or grouping qualities together, we are making a claim about the way the object is. He argues that this involves grouping properties together with something like necessity, but also says that this is not to deny that what properties the object has is contingent: "I do not mean to say 
that these representations necessarily belong to one another in the empirical intuition, but rather that they belong to one another in virtue of the necessary unity of the apperception in the synthesis of intuitions, i.e., in accordance with principles of the objective determination of all representations insofar as cognition can come from them." (B142) We need to think of the properties which belong together as properties of one object as hanging together in a way that is not up to me (which is not simply a function of my subjective association). There is a special kind of unity in the way they hang together, but this unity cannot be a further representation we get from experience (just as the unity of self-consciousness cannot be a further perception of some content of the mind). Kant says that:

\begin{abstract}
Objective significance cannot consist in the relation to another representation (of that which one would call the object), for that would simply raise anew the question: How does this representation in turn go beyond itself and acquire objective significance in addition to the subjective significance that is proper to it as a determination of the state of mind? If we investigate what new characteristic is given to our representations by the relation to an object, and what is the dignity that they thereby receive, we find that it does nothing beyond making the combination of representations necessary in a certain way, and subjecting them to a rule; and conversely that the objective significance is conferred on our representations only insofar as a certain order in their temporal relation is necessary. (A197=B242)
\end{abstract}

The unity of an object is not a matter of representing certain properties and then representing them together with some further representation of a unified thing; it is a matter of representing the properties of an object with a certain sort of unity. Kant says that "only in this way does there arise from this relation a judgment, i.e., a relation that is objectively valid" (B142). Only by synthesizing the representation of 'body' and 'heaviness' in such a way as to regard them as unified "in virtue of the necessary unity of the apperception in the synthesis of intuitions, i.e., in accordance with principles of the objective determination of all representations insofar as cognition can come from them" (B142) do I get an objectively valid judgment. He explains this by contrasting the thoughts 'If I carry a body, I feel a pressure of weight' and 'It, the body, is heavy,' where only the latter is objectively valid—it says something truth evaluable about a given object in the world. Kant says that in the second thought, the "two representations are combined in the object, i.e., regardless of any difference in the condition of the subject, and are not merely found together in perception" (B141).

So the claim is that representing objects with a certain kind of unity is necessary for us to be able to make judgments which are objective. Being able to think about something objective, an object, requires representing the manifold as united in a certain way. We do not have experience of an object until we have a certain way of unifying the manifold, and having the concept of an object in general is having the concept of a certain way of unifying the manifold. The claim is not that a certain kind of unity in consciousness is necessary for there to be an object, or that it constitutes the object, but that it constitutes the relation of representations to an object. It is necessary for me to experience something as an object. The creature which has merely subjective principles of association may have objects presented in its perceptual experience, but it doesn't experience them as objects, and it is not in a 
position to have referential thought about these objects. So saying that a certain kind of unity of the consciousness of the synthesis of the manifold of intuition constitutes the relation of representations to an object need not be seen as a metaphysical claim about what it is for the object to exist, but rather an epistemological claim about what it is to have a determinate referential thought about an object.

Kant thinks that in order to be able to represent the particulars given in perception as objects, to ascribe properties to them and investigate them empirically, we need a framework which provides a unity and necessity that governs the ascription of properties to particulars. Kant does not think that the categories add any determinate content to experience, rather, they contribute a kind of unity without which he thinks that we would not be able to think of objects as objects. In order to start ascribing properties to objects, we need to have some governing conception which controls which properties we are prepared to ascribe to the same object. Kant thinks that this requires rules which are a priori and irreducible, and that they are intimately connected to an a priori and irreducible representation of the unity of the self.

My concern here was not to defend, or even outline in proper detail, this part of Kant's argument in the Transcendental Deduction. Rather, my concern was with how it relates to idealism. I have suggested that one key issue we need to understand about the Deduction is why we should think that applying empirical concepts to objects should require concepts or rules containing necessity and universality. Further, I have suggested that at least one line of thought Kant presents in support of the claim that applying empirical concepts to objects depends on the application of a priori concepts does not depend on idealism. Of course, it is compatible with this that this line of thought leads to idealism with respect to the contribution of the categories, and my argument is compatible with a number of accounts of the idealism that it could lead to.

However, an alternative to seeing the Deduction as leading to a contribution by the mind to the world that exactly parallels that of the Aesthetic, is to see Kant's point as being simply that the Deduction is limited by the results of the Aesthetic: the categories can be used only for cognition of things that are given in experience. This would not result in weakening Kant's idealism, because it would still be the case that we have knowledge only of mind-dependent appearances, and not of things as they are in themselves. We can use the categories only for cognition of what is given in intuition, and what is given in intuition are mind-dependent appearances. We do not deny that ground-consequence relationships exist in things as they are in themselves, but we can use the concept of causation only to give us knowledge of things that we experience, and these things are thoroughly mind-dependent in the sense that they are dependent on our forms of intuition. We have no insight into necessity in the world as it is independent of us, and we have no grounds for making causal claims about anything other than things which can be given to us in intuition. We have no insight into the nature of substance in general, we simply know that we must experience something persisting. On this reading, the Deduction fits into a thoroughgoing idealist picture, even though, on its own, it neither entails this idealism nor depends on it. 
Acknowledgements A version of this article was presented at the conference Kant's Transcendental Logic \& Idealism in Amsterdam, May 2008; thanks to the participants for comments, and to Dennis Schulting for inviting me to speak at the conference. For reading and commenting on the manuscript, thanks to Quassim Cassam and Thad Metz.

\section{References}

Abela, P. 2002. Kant's Empirical Realism. Oxford: Clarendon Press.

Allais, L. 2007. 'Kant's Idealism and the Secondary Quality Analogy'. Journal of the History of Philosophy 45(3): 459-484.

Allais, L. 2009. 'Kant, Non-Conceptual Content, and the Representation of Space'. Journal of the History of Philosophy 47(3): 383-413.

Ameriks, K. 1990. 'Kant, Fichte, and Short Arguments to Idealism'. Archiv für Geschichte der Philosophie 72: 63-85.

Ameriks, K. 2003. Interpreting Kant's Critiques. Oxford: Clarendon Press.

Ameriks, K. 2006. Kant and the Historical Turn. Oxford: Clarendon Press.

Bird, G. 1962. Kant's Theory of Knowledge. London: Routledge \& Kegan Paul.

Campbell, J. 2002. Reference and Consciousness. Oxford: Clarendon Press.

Cassam, Q. 1987. 'Transcendental Arguments, Transcendental Synthesis and Transcendental Idealism'. The Philosophical Quarterly 37: 355-378.

Collins, A. 1999. Possible Experience. Berkeley and Los Angeles: University of California Press.

Dryer, D.P. 1966. Kant's Solution for Verification in Metaphysics. London: George Allen \& Unwin.

Falkenstein, L. 1995. Kant's Intuitionism. Toronto: Toronto University Press.

Gardner, S. 1999. Kant and the Critique of Pure Reason. London and New York: Routledge.

Kant, I. 1998. Critique of Pure Reason, Trans. and ed. P. Guyer and A. Wood. Cambridge: Cambridge University Press.

Langton, R. 1998. Kantian Humility: Our Ignorance of Things in Themselves. Oxford: Clarendon Press.

Longuenesse, B. 2006. 'Kant on a priori Concepts: the Metaphysical Deduction of the Categories'. In P. Guyer (ed.). The Cambridge Companion to Kant and Modern Philosophy. Cambridge: Cambridge University Press, pp. 129-168.

Pogge, T. 1991. 'Erscheinungen und Dinge an sich'. Zeitschrift für philosophische Forschung 45: 489-510.

Prauss, G. 1974. Kant und das Problem der Dinge an sich. Bonn: Bouvier Verlag.

Putnam, H. 1981. Reason, Truth and History. Cambridge: Cambridge University Press.

Rosefeldt, T. 2007. 'Dinge an sich und sekundäre Qualitäten'. In J. Stolzenburg (ed.), Kant in der Gegenwart. Berlin and New York: Walter de Gruyter, pp. 167-209.

Strawson, P.F. 1966. The Bounds of Sense. London: Methuen.

Van Cleve, J. 1995. 'Putnam, Kant and Secondary Qualities'. Philosophical Papers 24: 83-109.

Van Cleve, J. 1999. Problems from Kant. New York: Oxford University Press.

Ward, A. 2006. Kant: The Three Critiques. Cambridge: Polity Press.

Watkins, E. 2002. 'Kant's Transcendental Idealism and the Categories'. History of Philosophy Quarterly 19: 191-215. 